Research Paper:

\title{
The Status of Ageism in Caring for Elderly Patients From Nurses' Perspective
}

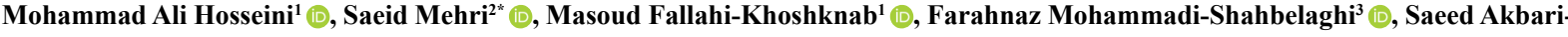 \\ Zardkhaneh $^{4}$ (1)
}

1. Department of Nursing, School of Nursing, University of Social Welfare and Rehabilitation Sciences, Tehran, Iran. 2. Department of Nursing, School of Nursing and Midwifery, Ardabil University of Medical Sciences, Ardabil, Iran.

3. Department of Nursing, Iranian Research Center of Aging, University of Social Welfare and Rehabilitation Sciences, Tehran, Iran.

4. Department of Psychology, School of Education and Psychology, Shahid Beheshti University, Tehran, Iran.

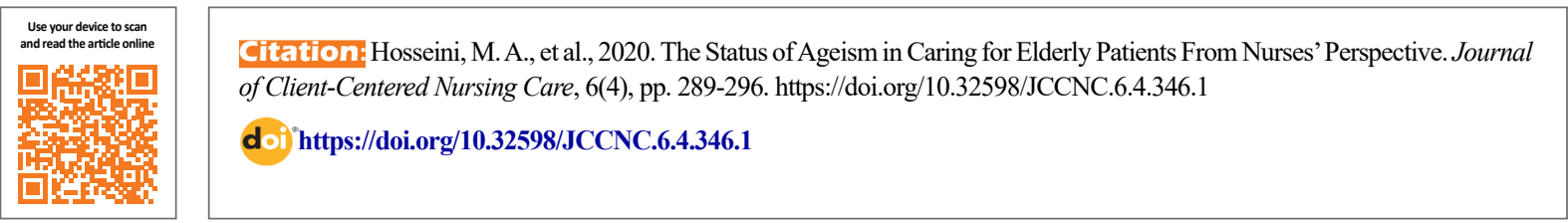

\section{(c) (1) (5)}

Article info:

Received: 13 Jan 2020

Accepted: 25 Aug 2020

Published: 01 Nov 2020

Keywords:

Ageism, Discrimination, Prejudice, Caring, Iran

\section{A B S T RA C T}

Background: As the number of elderly people referred to hospitals increases, so does the number of discrimination reports in the care of the elderly, compared with younger people. This study aimed to investigate the status of ageism in caring for elderly patients from nurses' perspective.

Methods: It was a descriptive cross-sectional study that was conducted in three selected hospitals of Ardabil province, Iran, in 2019. A total of 482 nurses were recruited by convenience sampling. The data were collected using a demographics questionnaire and the Ageism Scale in Hospital Care and analyzed using descriptive (frequency, percentage, mean, and standard deviation) and inferential statistics (the Pearson correlation coefficient, independent t-test, one-way ANOVA, and Scheffe post hoc test) in SPSS V. 20.

Results: The mean age of the participants was 33 years. Most nurses showed moderate ageism when providing care to older adults. The level of ageism was significantly associated with age $(\mathrm{P}=0.002)$, gender $(\mathrm{P}=0.001)$, work experience $(\mathrm{P}=0.032)$, and the ward in which the nurses worked $(\mathrm{P}=0.001)$

Conclusion: The findings revealed that the study hospitals suffered ageism. Also, the level of ageism was associated with the age, gender, admission ward, and work experience of the nurses. Thus, it is suggested to consider appropriate interventions to prevent ageism, when designing and planning care for older adults.

\section{"Corresponding Author:}

Address: Department of Nursing, School of Nursing and Midwifery, Ardabil University of Medical Sciences, Ardabil, Iran

Tel: +98 (914) 3558732

E-mail: mehrisaid338@gmail.com 


\section{Highlights}

- This study showed the existence of ageism in older adult care.

- The level of ageism was associated with age, gender, work experience, and the ward in which the nurses worked.

- The results of the study have important implications for further research and suggest the development of interventions to decrease ageism in practice.

\section{Plain Language Summary}

Ageism is defined as discrimination due to age in the provision of care to the elderly. Evidence shows that caregivers are unaware of their discriminatory treatment of the elderly. The evaluation of care by the care provider system positively impacts the acceptance and provision of qualified caregiving to older people. Thus, it is important to determine the status of ageism in caring for elderly patients, in hospitals, in the Iranian context. Nurses in this study showed a discriminatory view in providing care for the elderly. Moreover, the discriminatory view was related to the age, gender, work experience, and the ward in which the nurses worked.

\section{Introduction}

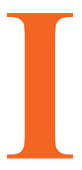

ncreased life expectancy and the growing population of the elderly are the important outcomes of the $21^{\text {st }}$ century (Hosseini et al., 2016; Liu, Norman \& While 2015). According to the 2016 census of the Statistical Center of Iran, adults older than 65 years comprise 6.1 million of the 80 million people in Iran (Statistical Center of Iran 2017). It is predicted that the population older than 60 years will constitute more than $10 \%$ and $20 \%$ of the Iranian population in 2021 and 2050, respectively (Hosseini et al., 2016). Following this increase, the older adult's health has become a challenge for healthcare systems in developing and developed countries (Adib-Hajbaghery, Mohamadghasabi \& Masoodi 2014). Therefore, managing problems related to older adults requires planning and policy-making (Amini \& Nosratabadi 2019).

Older adults used to receive more respect, but they receive less respect because of difficult living conditions and changes in the family structure (Liu, Norman \& While 2015). Negative attitudes and stereotypes, such as viewing older adults as weak, sensitive, and dependent people are prevalent worldwide (Butler 1969). Besides, this problem is exacerbated in hospitals with a high number of visits from older adults (Liu, Norman \& While 2013). In healthcare centers, the lack of attention to care for older adults partly results from an increased number of patients and staff shortage (Ben-Harush et al., 2017); this reduces the quality and quantity of care provided to older adults, compared with that provided to other patients (Officer et al., 2016). It also makes older adults be viewed as barriers to economic growth and responsible for increasing healthcare costs (Allen 2016; Mehri et al., 2020b).

In addition to reducing respect for the elderly, these factors understate the care of the elderly with a more inadequate prognosis (Lioyd-Sherlock et al., 2016). Ageism is the major cause of this neglect in older adult care (São José \& Amado 2017; São José et al., 2019). Ageism was first defined by Butler and means discrimination or prejudice against one age group compared with other age groups (Butler 1969). São José and Amado introduced ageism as follows: "Ageism is defined as negative or positive stereotypes, prejudice and/or discrimination against (or to the advantage of) us on the basis of our chronological age or on the basis of a perception of us as being 'old', 'too old', 'young', or 'too young.' Ageism can be self-directed or other-directed, implicit or explicit, and expressed on a micro, meso, or macro-level" (São José \& Amado 2017). Studies on health professionals demonstrate both positive and negative attitudes toward older people (Ben-Harush et al., 2017; Butler 1969; Liu Norman \& While 2015). The prejudice, beliefs, values attitudes, and behaviors of health professionals toward older people are important, as they impact the quality of care (Mehri et al., 2020b).

Nurses are the largest group of healthcare providers to older adults in hospitals (Melia \& Choowattanapakorn 2016). Moreover, studies report the existence of ageism in older adult care (Liu, Norman \& While 2015; Mehri et al., 2020a). Studying ageism in hospitals can increase the nurses' knowledge and awareness of ageism (Cowan 
et al., 2004), and facilitates the identification of discrimination and planning for its resolving. Thus, this study aimed to investigate the status of ageism in caring for elderly patients from nurses' perspective.

\section{Materials and Methods}

\section{Setting and sample}

This descriptive cross-sectional study was conducted between January and May 2019, in three teaching hospitals (Imam Reza, Dr Fatemi, and Imam Khomeini with overall 693 beds) affiliated to the Ardabil University of Medical Sciences. The study population included all 650 nurses working in these hospitals. It is worth mentioning that the citizens of the Ardabil province have Azeri ethnicity and speak the Azeri Turkish language. The inclusion criteria were willingness to participate and having a minimum of two years of work experience in older adult care.

\section{Instruments}

The Ageism Scale in Hospital Care (Mehri et al., 2019), was used to collect the data. This scale includes two parts. The first part examines demographic information, including age, gender, ward, work experience, education level, and employment status. The second part examines ageism in the hospital care setting. This scale has 20 items, with six items evaluating self-directed ageism and 14 items evaluating other-directed ageism. Also, responses are scored on a 6-point Likert scale from "completely disagree" $=1$ to "completely agree" $=6$. The scores range from a minimum of 20 to a maximum of 120 . The score ranges of 20 to 53,54 to 87 , and 88 to 120 respectively indicate weak, moderate, and severe ageism in the provision of care to older adults. This scale has a content validity index of 0.89 , the Cronbach alpha of 0.90 , and an intracluster correlation of 0.98 (Mehri et al., 2019). In this study, the Cronbach alpha was calculated as 0.91 .

\section{Procedure}

After obtaining the required permissions, the objectives of the study were explained to the participants, and informed and verbal consent was obtained from them upon visiting the study setting. All the nurses met the inclusion criteria, thus, the data collection tool was distributed to all 650 nurses, and 550 of them returned the completed questionnaire; 68 questionnaires were unusable, and finally, 482 questionnaires were analyzed.

\section{Data analysis}

The data were analyzed by descriptive (frequency, percentage, mean, and standard deviation) and inferential statistics (the Pearson correlation coefficient, independent t-test, one-way ANOVA, and Scheffe post hoc test) using SPSS V. 20.

\section{Results}

The Mean \pm SD age of the subjects was $33 \pm 6$ years. Table 1 represents the relationship between ageism and the demographic information of the study participants.

In this study, 159, 259, and 31 participants $(33 \%$, $60.6 \%$, and $6.4 \%$, respectively) respectively showed weak, moderate, and severe ageism when providing care to older adults. Table 2 shows the mean and SD of the scores in each subscale.

The Pearson correlation coefficient was used to examine the correlation between ageism and the nurses' age and work experience. According to Table 1, ageism is negatively correlated with the nurses' age $(\mathrm{P}=0.002, \mathrm{r}=-0.142)$.

Table 1 also reveals a 2-tailed significance level of 0.032 for the Pearson correlation test between ageism and nurses' work experience; this value is less than 0.05 (the minimum significance level). Thus, ageism is significantly and negatively associated with the nurses' work experience. To examine the relationship between ageism and the nurses' gender, an independent t-test was performed; the calculated t value was significant at the 0.05 level ( $\mathrm{P} \leq 0.05$; Table 1$)$. Therefore, the level of ageism differs by gender; the mean score was higher among male nurses (66.33), compared with female nurses (58.62).

Moreover, according to the 1-way ANOVA results (Table 3), ageism is significantly related to the admission ward. Specifically, the minimum value of ageism in one ward differs from that in the others. The Scheffe post hoc test was run to find the source of this difference, i.e. to identify the ward, the mean score of which differs from those of the rest.

Table 4 shows a significant difference in the mean score of ageism between the nurses working in the internal medicine ward and those working in the surgery ward. Also, the mean score of ageism significantly differs between nurses working in the internal medicine ward and those working in the intensive care unit. However, the differences were insignificant in other comparisons. 
Table 1. Relationship between ageism and study participants' demographic data $(\mathrm{N}=482)$

\begin{tabular}{|c|c|c|c|c|c|}
\hline \multirow{2}{*}{ Variable } & \multirow{2}{*}{ Category } & \multirow{2}{*}{ No. (\%) } & \multirow{2}{*}{ Mean \pm SD } & \multicolumn{2}{|c|}{ Results } \\
\hline & & & & Test & $\mathbf{P}$ \\
\hline \multicolumn{2}{|l|}{ Age, y } & 482 & $33 \pm 6.9$ & $r=-0.142$ & 0.002 \\
\hline \multirow{3}{*}{ Gender } & Male & 160 (33) & & \multirow{3}{*}{$t=4.85$} & \multirow{3}{*}{0.000} \\
\hline & & & & & \\
\hline & Female & 322 (67) & & & \\
\hline \multirow{3}{*}{ Marital status } & Single & $145(31)$ & & \multirow{3}{*}{$t=1.76$} & \multirow{3}{*}{0.342} \\
\hline & & & & & \\
\hline & Married & 337 (69) & & & \\
\hline \multirow{3}{*}{ Educational status } & Associate & $14(2.9)$ & & \multirow{3}{*}{$F=2.23$} & \multirow{3}{*}{0.108} \\
\hline & Bachelor's & $424(88)$ & & & \\
\hline & Master's & $44(9.1)$ & & & \\
\hline \multicolumn{2}{|l|}{ Work experience } & & $9.10 \pm 6.07$ & $r=0.097$ & 0.032 \\
\hline \multirow{5}{*}{ Working unit } & Emergency & $128(26.6)$ & & \multirow{5}{*}{$F=4.83$} & \multirow{5}{*}{0.001} \\
\hline & Surgery & $76(15.8)$ & & & \\
\hline & Internal & $61(12.7)$ & & & \\
\hline & $\begin{array}{l}\text { Intensive } \\
\text { care }\end{array}$ & $128(26.6)$ & & & \\
\hline & Others & 89 (18.5) & & & \\
\hline \multirow{5}{*}{ Employment status } & Treaty & $92(19.1)$ & & \multirow{5}{*}{$F=2.32$} & \multirow{5}{*}{0.056} \\
\hline & Permanent & $196(40.7)$ & & & \\
\hline & Contractual & $14(30.1)$ & & & \\
\hline & Temporary & $21(4.4)$ & & & \\
\hline & Corporative & $28(5.8)$ & & & \\
\hline
\end{tabular}

Client- Centered Nursing Care

\section{Discussion}

This study aimed to investigate the status of ageism in caring for elderly patients from nurses' perspective. Based on the results, most of the nurses showed moderate ageism when providing care to older adults. This finding was consistent with another study that indicated a moderate level of ageism among nurses who worked in a clinical setting. As members of society, nurses are not protected from this ageist attitude, which may influence the professional practice for elder people (Melia \& Choowattanapakorn 2016). Moreover, ageist attitudes toward the elderly would negatively affect the care provision for the elderly patients (Hanson 2014).

Table 2. Subscales of the ageism scale in the hospital care and the total score of the scale

\begin{tabular}{cccc}
\hline Subdimensions of the Scale & Total Items & Min, Max & Mean \pm SD \\
\hline Self-directed & 6 & 6,36 & $23.31 \pm 5.95$ \\
Other-directed & 14 & 14,84 & $37.87 \pm 13.18$ \\
Total & 20 & 20,120 & $61.18 \pm 1.7$ \\
\hline
\end{tabular}


Table 3. One-way ANOVA for ageism and ward

\begin{tabular}{ccccc}
\hline Variable & Groups & Sum of Squares & df & Mean Squares \\
\hline & Between Groups & 5398.841 & 4 & 1349.710 \\
Working ward & Within Groups & 133236.520 & 477 & 279.322 \\
\hline
\end{tabular}

A study conducted at the University of South Australia in Queensland examined the attitudes of final-year nursing students towards aging to emancipate them to cope with these issues and prevent the recurrence of aging in their future performance as registered nurses. The social critical theory together with the Stringer participatory action research model guided the theoretical directions of this study. Nine final-year students volunteered. Data were collected through focus group meetings and clinical diary for six months. The findings of this study showed acute self-awareness about the meaning of aging and personal fear of the aging process (De la Rue et al., 2003). Since older adults constitute the majority of patients admitted to hospitals, these results highlight the importance of paying attention to the provision of highquality care without discrimination for this age group.

Based on the findings, as the nurses' age increased, their level of ageism decreased, and vice versa. This result is consistent with studies expressing that older caregivers provide better care to older adults (Blegen, Vaughn \& Goode 2001; Mion et al., 2006). Also, compared with younger nurses, older and more experienced nurses provide better care (Melia \& Choowattanapakorn 2016). Moreover, older participants provided better care to older adults (Lambrinou et al., 2009; Chen \& Walsh 2009; Söderhamn, Lindencrona \& Gustavsson 2001). In a study conducted in Iran, negative attitudes toward elderly people were more severe in high school students, compared with university students (Sum, Emamian\& Sefidchian 2016). However, some other studies reported no significant difference between the nurses' attitudes towards older patients and their demographic characteristics, such as age, gender, and work department (Polat et al., 2014; Sahin et al., 2012).

Results of this study showed that as the work experience of nurses increased, their degree of ageism decreased. Similar studies also reported that those with an experience of working with older adults had a positive attitude towards their care (Melia \& Choowattanapakorn 2016; Özer \& Terkeş, 2014; Sum, Emamian\& Sefidchian 2016). Results of some other studies are congruent with our findings (Hughes et al., 2008; Wilkinson, Gower \& Sainsbury 2002; Mclafferty \& Morrison 2004). Similarly, Leung and colleagues determined that nurses with experience in elderly patient care held significantly more positive attitudes than those with no experience. Nurses who have experience in working with elderly patients demonstrate positive behavior, because of increased knowledge concerning older patients' care, the development of communication with elderly patients, and an increased awareness of issues specific to older patients care and the process of aging (Leung et al., 2011). While some studies found no association between ageism and the experience of working with older people (Hweidi \& Al-Obeisat 2006; Pan, Edwards \& Chang 2009).

Based on the results of the present study, the degree of ageism in hospital care differs between men and women. The findings showed that ageism for older adults had a better and more satisfactory status in female nurses than

Table 4. Pairwise comparison by the Scheffe post hoc test (dependent variable: ageism)

\begin{tabular}{|c|c|c|c|c|c|}
\hline Wards & Mean士SD & Emergency & Surgery & Internal Medicine & Intensive Care \\
\hline Emergency & $62.96 \pm 17.08$ & & & & \\
\hline Surgery & $56.97 \pm 15.35$ & NS & & & \\
\hline Internal medicine & $67.45 \pm 16.24$ & NS & $*$ & & \\
\hline Intensive care & $58.17 \pm 14.61$ & NS & NS & $*$ & \\
\hline Other & $62.19 \pm 20.09$ & NS & NS & NS & NS \\
\hline
\end{tabular}

NS: Not Significant; *A significant difference based on the Scheffe test.

Client- Centered Nursing Care 
in male nurses. In this regard, female university students have shown a more positive attitude towards older adult care, compared with their male counterparts (Deary et al., 1993; Fitzgerald et al., 2003; Wang et al., 2009). Also, in studies by Özer and Terkeş (2014) and Mcconatha et al. (2004) women showed less ageism for older adult care, compared with men. The results of these studies are in line with the present findings, which may be related to the caregiving role played by women in families. However, this result is inconsistent with some other studies reporting that gender weakly affects older adult care (Melia \& Choowattanapakorn 2016).

In the present study, ageism in the provision of care to older adults significantly differed considering the ward in which the nurses worked; the highest degree of ageism was reported in the internal medicine ward. On the other hand, the lowest level of ageism was found in the surgery ward, in which the length of stay is short. Some similar studies reported that ageism is more severe in clinical nurses and some wards compared with others (Brown et al., 2008; Melia \& Choowattanapakorn 2016). This result may be due to the working conditions of nurses providing care to older patients, eg, the number of nurses per patient, the chronic conditions of the patients, and their long-term stay in this ward.

\section{Conclusion}

The findings revealed the existence of ageism in the study hospitals and showed that the severity of ageism decreases as the nurses' age and work experience increase. Moreover, the degree of ageism in older adult care is lower in women than in men. Also, the highest level of ageism was seen in the internal medicine ward, in which older adults stay for a longer time. The main limitation of this study was the self-report nature of the data collection tool. The emotional and psychological status of the nurses at the time of filling in the questionnaire could have affected the results of the study; this factor could not be controlled by the researcher. Besides, the present study was carried out on nurses working in a specific region in Iran. Therefore, these findings may not be generalizable to all nurses.

It is recommended to further investigate the factors influencing ageism against the elderly people among nurses. It is also suggested to conduct a similar study in other provinces and countries, so more reliable and valid conclusions can be drawn by the comparison of the results of different studies. Future studies are also suggested to examine the factors affecting ageism in hospital care. Moreover, interventional studies are suggested to be planned to improve the attitude of nurses working with elderly people in nursing homes, hospitals, and community health care settings.

\section{Ethical Considerations}

\section{Compliance with ethical guidelines}

This article was approved by the Research Ethics Committee of the University of Social Welfare and Rehabilitation Sciences (Code: IR.USWR.REC.2018.263). Besides, all the subjects signed the informed consent.

\section{Funding}

The present paper was extracted from the $\mathrm{PhD}$. dissertation of the corresponded author in the Department of Nursing, University of Social Welfare and Rehabilitation Sciences.

\section{Authors' contributions}

All authors contributed in preparing this article.

\section{Conflict of interest}

The authors declared no conflict of interest.

\section{Acknowledgments}

The authors would like to thank the Deputy of Research and Technology, Department of Nursing at the University of Social Welfare and Rehabilitation Sciences, and the nursing participants for their valuable cooperation.

\section{References}

Adib-Hajbaghery, M., Mohamadghasabi, M. \& Masoodi, A. N., 2014. [Effect of an elderly care program on the nursing students' attitudes toward the elderly (Persian)]. Iranian Journal of Ageing, 9(3), pp. 189-96. http://salmandj.uswr.ac.ir/browse. php?a_id $=662 \&$ sid $=1 \&$ slc_lang $=$ en

Allen, J. O., 2016. Ageism as a risk factor for chronic disease. The Gerontologist, 56(4), pp. 610-4. [DOI:10.1093/geront/gnu158] [PMID]

Amini, M., \& Nosratabadi, M., 2019. Assessing the met and unmet needs among elderly people in Isfahan, Iran: A mixed method. Journal of Gerontology and Geriatrics, 67, pp. 195-9. http:// www.jgerontology-geriatrics.com/article/view/28

Ben-Harush, A., et al., 2017. Ageism among physicians, nurses, and social workers: Findings from a qualitative study. European Journal of Ageing, 14, pp. 39-48. [DOI:10.1007/s10433-0160389-9] [PMID] [PMCID] 
Blegen, M. A., Vaughn, T. E. \& Goode, C. J., 2001. Nurse experience and education: Effect on quality of care. The Journal of Nursing Administration, 31, pp. 33-9. [DOI:10.1097/00005110200101000-00007] [PMID]

Brown, J., et al., 2008. Transforming students' views of gerontological nursing: Realising the potential of enriched environments of learning and care: A multi-method longitudinal study. International Journal of Nursing Studies, 45(8), pp. 1214-32. [DOI:10.1016/j.ijnurstu.2007.07.002] [PMID]

Butler, R. N., 1969. Age-ism: Another form of bigotry. The Gerontologist, 9(4), pp. 243-6. [DOI:10.1093/geront/9.4_Part_1.243] [PMID]

Chen, S. \& Walsh, S. M., 2009. Effect of a creative-bonding intervention on Taiwanese nursing students' self-transcendence and attitudes toward elders. Research in Nursing \& Health, 32, pp. 204-16. [DOI:10.1002/nur.20310] [PMID]

Cowan, D. T., et al., 2004. Measuring the knowledge and attitudes of health care staff toward older people: Sensitivity of measurement instruments. Educational Gerontology, 30, pp. 237-54. [DOI:10.1080/03601270490273169]

Deary, I. J., et al., 1993. Geriatric medicine: Does teaching alter medical students' attitudes to elderly people? Medical Education, 27, pp. 399-405 [DOI:10.1111/j.1365-2923.1993.tb00292.x] [PMID]

De la Rue, M., 2003. Preventing ageism in nursing students: an action theory approach. The Australian Journal of Advanced Nursing. Australian Nursing and Midwifery Federation, 20(4), pp. 8-14. https://search.informit.org/doi/10.3316/informit.405292425641263

Fitzgerald, J. T., et al., 2003. Relating medical students' knowledge, attitudes, and experience to an interest in geriatric medicine. The Gerontologist, 43(6), pp. 849-55. [DOI:10.1093/ geront/43.6.849] [PMID]

Hanson, R. M., 2014. 'Is elderly care affected by nurse attitudes?' A systematic review. British Journal of Nursing, 23(4), pp. 225-9. [DOI:10.12968/bjon.2014.23.4.225] [PMID]

Hosseini, R. S., et al., 2016. Validity and reliability of Self Rated Health (SRH) measure among Iranian community-dwelling older adults. Journal of Gerontology and Geriatrics, 67(2), pp. 103-8. http:/ / www. jgerontology-geriatrics.com/article/view/53

Hughes, N. J., et al., 2008. Medical student attitudes toward older people and willingness to consider a career in geriatric medicine. Journal of the American Geriatrics Society, 56(2), pp. 334-8. [DOI:10.1111/j.1532-5415.2007.01552.x] [PMID]

Hweidi, I. M., \& Al-Obeisat, S. M., 2006. Jordanian nursing students' attitudes toward the elderly. Nurse Education Today, 26(1), pp. 23-30. [DOI:10.1016/j.nedt.2005.06.003] [PMID]

Lambrinou, E., et al., 2009. Attitudes and knowledge of the Greek nursing students towards older people. Nurse Education Today, 29(6), pp. 617-22. [DOI:10.1016/j.nedt.2009.01.011] [PMID]

Leung, S., et al., 2011. Hospital doctors' attitudes towards older people. Internal Medicine Journal, 41(4), pp. 308-14. [DOI:10.1111/j.1445-5994.2009.02140.x] [PMID]

Lioyd-Sherlock, P. G., et al., 2016. Institutional ageism in global health policy. The BMJ, 354, p. i4514. [DOI:10.1136/bmj.i4514] [PMID]
Liu, Y. E., Norman, I. J. \& While, A. E., 2013. Nurses' attitudes towards older people: A systematic review. International Journal of Nursing Studies, 50(9), pp. 1271-82. [DOI:10.1016/j.ijnurstu.2012.11.021] [PMID]

Liu, Y. E., Norman, I. J. \& While, A. E., 2015. Nurses' attitudes towards older people and working with older patients: An explanatory model. Journal of Nursing Management, 23(8), pp. 965-73. [DOI:10.1111/jonm.12242] [PMID]

Mcconatha, J. T., et al., 2004. Turkish and US attitudes toward aging. Educational Gerontology, 30, pp. 169-83. [DOI:10.1080/03601270490272106]

Mclafferty, I. \& Morrison, F., 2004. Attitudes towards hospitalized older adults. Journal of Advanced Nursing, 47(4), pp. 446-53. [DOI:10.1111/j.1365-2648.2004.03122.x] [PMID]

Mehri, S., et al., 2019. Designing and validation of "ageism scale in hospital care" (Phd. dissertation), University of Social Welfare and Rehabilitation Sciences.

Mehri, S., et al., 2020a. Explaining nurses' perception of the causes of ageism in hospital settings. Electronic Journal of General Medicine, 17(5), p. em218. [DOI:10.29333/ejgm/7881]

Mehri, S., et al., 2020b. Clarification of ageism in the care system. Salmand: Iranian Journal of Ageing, 15(1), pp. 14-27. [DOI:10.32598/sija.2020.3.170]

Melia, S., \& Choowattanapakorn, T., 2016. The relationship between nurses' characteristics, ageism, perception of older people's care and nursing practice in hospitalized older people. Journal of Health Research, 30(2), pp. 109-14. https:/ / www researchgate.net/profile/Tassana-Choowattanapakorn/publication/304553327

Mion, L. C., et al., 2006. Retaining and recruiting mature experienced nurses: A multicomponent organizational strategy. The Journal of Nursing Administration, 36(3), pp. 148-54. [DOI:10.1097/00005110-200603000-00009] [PMID]

Officer, A., et al., 2016. Valuing older people: Time for a global campaign to combat ageism. Bulletin of the World Health Organization, 94, pp. 710-11. [DOI:10.2471/BLT.16.184960] [PMID] [PMCID]

Özer, Z. C., \& Terkeş, N., 2014. Evaluation of nursing student's attitudes towards ageism in Turkey. Procedia-social and Behavioral Sciences, 116, pp. 2512-5. [DOI:10.1016/j.sbspro.2014.01.602]

Pan, I. J., Edwards, H., \& Chang, A., 2009. Taiwanese nursing students' attitudes toward older people. Journal of Gerontological Nursing, 35, pp. 50-5. [DOI:10.3928/00989134-20090903-01] [PMID]

Polat, Ü., et al., 2014. Nurses' and physicians' perceptions of older people and attitudes towards older people: Ageism in a hospital in Turkey. Contemporary Nurse, 48, pp. 88-97. [DOI:10 .1080/10376178.2014.11081930] [PMID]

Sahin, S., et al., 2012. Attitudes toward the elderly among the health care providers: Reliability and validity of Turkish version of the UCLA Geriatrics Attitudes (UCLA-GA) scale. Archives of Gerontology and Geriatrics, 55, pp. 205-9. [DOI:10.1016/j. archger.2011.08.015] [PMID]

São José, J. M. S., \& Amado, C. A. F., 2017. On studying ageism in long-term care: a systematic review of the literature International Psychogeriatrics, 29, pp. 373-87. [DOI:10.1017/ S1041610216001915] [PMID] 
São José, J. M. S., et al., 2019. Ageism in health care: A systematic review of operational definitions and inductive conceptualizations. The Gerontologist, 59, pp. 98-108. [DOI:10.1093/ geront/gnx020] [PMID]

Söderhamn, O., Lindencrona, C. \& Gustavsson, S. M., 2001. Attitudes toward older people among nursing students and registered nurses in Sweden. Nurse Education Today, 21, pp. 225-9. [DOI:10.1054/nedt.2000.0546] [PMID]

Statistical Center of Iran, 2017. Pulation-and-Housing-Censusess, Iran, Statistical Center of Iran, Viewed 19 April 2021, https://www.amar.org.ir

Sum, S., Emamian, S., \& Sefidchian, A,. 2016. Aging educational program to reduce ageism: Intergenerational approach. Elderly Health Journal, 2(1), pp. 33-38. http:/ / ehj.ssu.ac.ir/article1-53-en.html

Wang, C. C., et al., 2009. Taiwanese medical and nursing student interest levels in and attitudes towards geriatrics. Annals Academy of Medicine Singapore, 38(3), pp. 230-6. https:// pubmed. ncbi.nlm.nih.gov/19347077/

Wilkinson, T. J., Gower, S., \& Sainsbury, R., 2002. The earlier, the better: The effect of early community contact on the attitudes of medical students to older people. Medical Education, 36(6), pp. 540-2. [DOI:10.1046/j.1365-2923.2002.01226.x] [PMID] 